\title{
Phylogenetic diversity of Synechococcus in the Chesapeake Bay revealed by Ribulose-1,5- bisphosphate carboxylase-oxygenase (RuBisCO) large subunit gene (rbcL) sequences
}

\author{
Feng Chen ${ }^{1, * * *}$, Kui Wang ${ }^{1, * *}$, Jinjun Kan ${ }^{1}$, Dave S. Bachoon ${ }^{2}$, Jingrang Lu ${ }^{3}$, \\ Stanley Lau ${ }^{4}$, Lisa Campbell ${ }^{5}$ \\ ${ }^{1}$ Center of Marine Biotechnology, University of Maryland Biotechnology Institute, Baltimore, Maryland 21042, USA \\ ${ }^{2}$ Department of Biological and Environmental Sciences, Georgia College and State University, Milledgeville, \\ Georgia 31061, USA \\ ${ }^{3}$ Department of Marine Sciences, University of Georgia, Athens, Georgia 30602, USA \\ ${ }^{4}$ Department of Biology, Hong Kong University of Science and Technology, Kowloon, Hong Kong \\ ${ }^{5}$ Department of Oceanography, Texas A\&M University, College Station, Texas 77843, USA
}

\begin{abstract}
In order to understand how Synechococcus in the estuarine environment (Chesapeake Bay) are phylogenetically related to other known marine Synechococcus, partial rbcL gene sequences from 25 strains of Synechococcus spp. isolated from estuarine, coastal and oceanic waters were sequenced. The rbcL gene phylogeny showed that Chesapeake Bay Synechococcus isolates together with other marine Synechococcus spp. formed a monophyletic group which belongs to the form IA RuBisCO. All the Chesapeake Bay Synechococcus were able to grow in a wide range of salinity (0 to $30 \%$ ), and most of them belong to the Marine Cluster B (MC-B). Interestingly, several phycoerythrin (PE)-containing Synechococcus isolated from the bay were clustered in the MC-B group, which had previously only contained the non-PE Synechococcus. A set of PCR primers was developed to specifically amplify the rbcL gene from natural marine Synechococcus populations. After screening 232 clones randomly selected from 5 clone libraries (built on 5 estuarine samples respectively), at least 7 different rbcL genotypes or the operational taxonomic units (OTUs) were identified. Despite the great genetic diversity among the OTU sequences, they were all clustered with 13 Chesapeake Bay isolates. The distribution frequency of these OTUs varied dramatically from the upper to lower bay. Our results suggest that the Chesapeake estuary provides an ideal environment for the MC-B type Synechococcus populations to thrive. Marine Synechococcus appear to adapt well to various ecological niches, and a clear boundary solely based on phenotypic features may not exist when more and more novel ecotypes and genotypes are unveiled with molecular tools.
\end{abstract}

KEY WORDS: Synechococcus $\cdot$ Estuary $\cdot \operatorname{rbcL}$ gene $\cdot$ Phylogeny $\cdot$ Classification Resale or republication not permitted without written consent of the publisher

\section{INTRODUCTION}

Phycobilisome-containing unicellular cyanobacteria of the genus Synechococcus are among the most abundant members of the picophytoplankton in the open ocean (Johnson \& Sieburth 1979, Waterbury et al. 1979). Marine Synechococcus species contribute 5 to
$30 \%$ of primary production in the surface waters of world's oceans (Waterbury et al. 1979). The Synechococcus group (Chroococcales) is a provisional assemblage that was loosely defined as unicellular coccoid to rod-shaped cyanobacteria $(<3 \mu \mathrm{m}$ in diameter) whose cells divided by binary fission in a single plane (Waterbury \& Rippka 1989). Based on morphological, physio- 
logical and chemical properties and DNA base ratios, Synechococcus spp. have been divided into 6 clusters: Cyanobacterium, Synechococcus, Cyanobium, Marine Clusters (MC) A, B, and C (Waterbury \& Rippka 1989). It is now known that MC-A, MC-B, the Cyanobium cluster and the Prochlorococcus group formed a monophyletic group, distinct from freshwater Synechococcus and the MC-C cluster (Fuller et al. 2003). All strains in the MC-A cluster contain phycoerythrin (PE) as their major light-harvesting pigment. PE-containing Synechococcus strains can be distinguished by the presence or absence of phycourobilin (PUB) and the ratio of PUB to phycoerythrobilin (PEB) contained in the individual cells. All strains in MC-B and MC-C contain only phycocyanin as their major light harvesting pigment, but do not contain PE (Waterbury \& Rippka 1989). Non-PE type is also called PC type in this study.

The PE type Synechococcus is a major primary producer in pelagic oceans (Campbell et al. 1983, Campbell \& Iturriaga 1988, Olson et al. 1990), and the phylogenetic relationship among PE isolates has been extensively examined (Wood \& Townsend 1990, Urbach et al. 1992, 1998, Toledo \& Palenik 1997, Toledo et al. 1999, Rocap et al. 2002, Fuller et al. 2003). Divergence of PE strains based on the 16S rDNA sequences appeared to be narrow $(<4 \%)$. The term 'microdiversity' has been used to describe a narrow genetic niche for unicellular cyanobacteria including Synechococcus and Prochlorococcus (Fuhrman \& Campbell 1998, Moore et al. 1998). The RNA polymerase gene (rpoC1) has been used to study the phylogenetic linkage among the PE type Synechococcus (Toledo \& Palenik 1997, Toledo et al. 1999). The rpoC1 based phylogeny appeared to correlate well with the motility of PE Synechococcus. Most recently, the phylogenetic study based on the $16 \mathrm{~S}-23 \mathrm{~S}$ ribosomal DNA internal transcribed spacer (ITS) sequences divided the MC-A Synechococcus into 6 clades (Rocap et al. 2002).

In order to further resolve the phylogeny of the MC-B strains, more Synechococcus strains isolated from coastal estuaries are needed. Compared with other Synechococcus clusters, MC-B is not a wellcharacterized group because it only contains 4 strains (WH8007, WH8101, WH5701, and PCC7001) (Waterbury \& Rippka 1989). Recently, WH8101 and PCC7001 have been re-classified into MC-A and the Cyanobium cluster, respectively (Herdman et al. 2001). Although marine Synechococcus and Prochlorococcus frequently co-exist in oceanic waters, the former dominates in coastal waters (Partensky et al. 1999). Chromatic adaptation by Synechococcus enables this group to adapt to broad ecological niches; a number of different genotypes or ecotypes of Synechococcus have been identified in natural environments (Palenik 2001, Ferris et al. 2003). It is now known that Synechococcus are also abundant and dynamic members of the plankton in coastal estuaries. For examples, the abundance of Synechococcus in the Bedford Basin varied from a few cells to $4.5 \times 10^{5} \mathrm{cells} \mathrm{ml}^{-1}$, and was greatly influenced by the temperature (Li 1998). The seasonal survey in the Chesapeake Bay showed that Synechococcus density reached the maximum of $1.3 \times$ $10^{6}$ cells $\mathrm{ml}^{-1}$ in the summer and dropped to the minimum of $4.9 \times 10^{2}$ cells ml ${ }^{-1}$ in the winter ( $\mathrm{K}$. Wang \& F. Chen unpubl. data). In a recent review, (Scanlan \& West 2002) indicated that Synechococcus from estuarine or coastal waters have not been well studied so far and are likely under-represented in Synechococcus culture collections and within phylogenetic trees as well. Is it possible that Synechococcus in coastal estuaries exhibit greater genetic diversity compared to the PE type, due to their complex habitats?

Ribulose 1,5-bisphosphate carboxylase-oxygenase ( $\mathrm{RuBisCO}$ ) is a key enzyme in the primary pathway of photosynthetic carbon fixation of all primary producers. RuBisCO catalyzes the assimilation of $\mathrm{CO}_{2}$ to organic carbon via the Calvin-Benson cycle. The enzyme is made of large and small subunits. The large subunit is responsible for carbon fixation (Miziorko \& Lorimer 1983). This enzyme has been found to have 2 natural forms, Forms I and II. Form I contains 8 large and 8 small subunits $\left(\mathrm{L}_{8} \mathrm{~S}_{8}\right)$, encoded by rbcL and rbcS, respectively. Form II is comprised of large subunits only, usually as a dimer $\left(\mathrm{L}_{2}\right)$ (Watson \& Tabita 1997). The Form I RuBisCOs are believed to have evolved in response to the decline of $\mathrm{CO}_{2}$ and the emergence of oxygen while the global atmosphere changed (McFadden \& Tabita 1974). According to the phylogeny of the rbcL gene, the Form I RuBisCOs can be divided into 4 different forms (A to D). Form IA consists of 2 marine cyanobacteria (marine Synechococcus WH7803 and Prochlorococcus marinus) and chemolithoautotrophs such as Chromatium vinosum, Thiobacillus denitrificans, and T. ferrooxidans (Watson \& Tabita 1997). Form IB contains chloroplasts of terrestrial plants, green algae and cyanobacteria (e.g. Anabaena, freshwater Synechococcus and Synechocystis, Prochloron). Form IC has been found in a few alpha- and deltaproteobacteria, and many non-green algae carry Form ID RuBisCO (Watson \& Tabita 1997). Unlike the ribosomal RNA genes which are universal for all living organisms, RuBisCO (the rbcL gene) is found primarily in photoautotrophs and chemolithotrophs. Because RuBisCO plays a central role in photosynthesis, the phylogenetic analyses based on the rbcL gene sequences have provided many new insights on the evolution of photosynthesis (Clegg 1993). The rbcL gene has been used as a phylogenetic marker to inves- 
tigate the genetic diversity of marine phytoplankton communities (Pichard et al. 1997) and microorganisms living in the deep-sea (Elsaied \& Naganuma 2001) and in groundwater (Alfreider et al. 2003).

In this study, our objective was to understand the phylogenetic diversity of Synechococcus living in the Chesapeake Bay, the largest and probably the most complex estuary in the US. The partial rbcL sequences from 13 Chesapeake Bay Synechococcus isolates and 12 Woods Hole Synechococcus isolates were sequenced and used for phylogenetic reconstruction. The rbcL gene phylogeny revealed that the vast majority of Chesapeake Bay Synechococcus isolates belong to the MC-B group. We also developed a new set of PCR primers specific to the rbcL gene of marine Synechococcus as a tool for exploring the genetic diversity of Synechococcus populations in the bay. The environmental rbcL sequences showed that Synechococcus living in the bay are diverse, but still closely related to Chesapeake Bay Synechococcus isolates.

\section{MATERIALS AND METHODS}

Synechococcus strains. Synechococcus strains used in this study are described in Table 1. The Chesapeake Bay Synechococcus spp. (with CB prefix) were isolated in our laboratory. To isolate CB strains, water samples collected from the bay were pre-incubated to increase Synechococcus density (Waterbury \& Willey 1988). A pour plating method (Brahamsha 1996) was used to isolate Synechococcus strains from the pre-incubated waters. Marine Synechococcus strains were grown in the SN medium (Waterbury et al. 1986) at $25^{\circ} \mathrm{C}$ in constant light (20 to $30 \mu \mathrm{E} \mathrm{m}^{-2} \mathrm{~s}^{-1}$ ) in an illuminated incubator. The salinity of SN media was adjusted to be close to the salinity of water samples. The motility was observed by phase-contrast microcopy using a wet mounts of cultures. Cultures of marine Synechococcus isolates WH7803, WH7805, WH8101 and WH8103 were provided by B. Binder at the University of Georgia and the other WH strains were from L. Campbell's laboratory. WH8007 and WH5701 were purchased from the Center for Culture of Marine Phytoplankton (CCMP) at Bigelow Laboratory (Maine, USA).

In vivo pigment absorption spectra. In vivo pigment absorption spectra for the Synechococcus strains isolated from Chesapeake Bay and some Woods Hole Synechococcus isolates were determined between 400 to $800 \mathrm{~nm}$ in $1 \mathrm{~nm}$ intervals using a Beckman DU640 spectrophotometer. Cultures $(2 \mathrm{ml})$ under exponential growth were used to measure the pigment absorption spectra of Synechococcus.

Enumeration of Synechococcus cells. To determine the Synechococcus abundance in a water sample, a $10 \mathrm{ml}$ water sample was filtered onto a $0.2 \mu \mathrm{m}$ pore size

Table 1. Synechococcus strains used in this study

\begin{tabular}{|c|c|c|c|c|c|c|}
\hline Strain & $\mathrm{PE}$ & PUB:PEB & Motility & Location & Source & Accession no. \\
\hline CB0101 & - & no PUB & + & Inner Harbor, CB & This study & AY244815 \\
\hline CB0102 & - & no PUB & - & Inner Harbor, CB & This study & AY244816 \\
\hline CB0103 & - & no PUB & - & Inner Harbor, CB & This study & AY244817 \\
\hline CB0104 & - & no PUB & - & Inner Harbor, CB & This study & AY244818 \\
\hline СB0201 & - & no PUB & - & Stn 818, CB & This study & AY244819 \\
\hline CB0203 & - & no PUB & - & Stn $818, C B$ & This study & AY452725 \\
\hline CB0204 & - & no PUB & - & Stn 707, CB & This study & AY244820 \\
\hline CB0205 & + & no PUB & + & Stn $818, C B$ & This study & AY244833 \\
\hline CB0206 & + & no PUB & + & Stn 707, CB & This study & AY452726 \\
\hline CB0207 & + & no PUB & + & Stn $707, \mathrm{CB}$ & This study & AY452727 \\
\hline CB0208 & + & no PUB & + & Stn $707, \mathrm{CB}$ & This study & AY452728 \\
\hline CB0209 & + & no PUB & - & Stn $707, \mathrm{CB}$ & This study & AY452729 \\
\hline CB0210 & + & no PUB & - & Stn $707, C B$ & This study & AY452730 \\
\hline WH5701 & - & no PUB & - & Long Island Sound & Guillard R & AY244822 \\
\hline WH8007 & - & no PUB & - & Gulf of Mexico & Provasoli L & AY244825 \\
\hline WH8101 & - & no PUB & - & WHOI Harbor & Valois F & AF081831 \\
\hline WH8102 & + & high & + & Sargasso Sea & Waterbury J & AF081832 \\
\hline WH8103 & + & high & + & Sargasso Sea & Waterbury J & AY244827 \\
\hline WH8108 & + & high & - & Sargasso Sea & Waterbury J & AY244831 \\
\hline WH7803 & + & low & - & Sargasso Sea (25 m) & Waterbury $\mathrm{J}$ & U46156 \\
\hline WH8104 & + & low & - & Sargasso Sea & Waterbury J & AY244828 \\
\hline WH8111 & + & low & - & Sargasso Sea & Waterbury J & AY244832 \\
\hline WH7805 & + & no PUB & - & Sargasso Sea & Brand L & AF081833 \\
\hline WH8006 & + & no PUB & - & Gulf of Mexico & Waterbury J & AY244824 \\
\hline WH8008 & + & no PUB & - & Gulf of Mexico & Waterbury J & AY244826 \\
\hline
\end{tabular}


$25 \mathrm{~mm}$ black polycarbonate membrane filter (Osmonics). A Nikon Eclipse E400 epifluorescence microscope was used to count the total Synechococcus cells, PC and PE type cells, respectively. The total cells were enumerated under green light excitation (528 to $553 \mathrm{~nm}$ ). Under blue light excitation (465 to $495 \mathrm{~nm}$ ), the PE cells showed bright yellow-orange color while the PC cells showed dim red in the same field. The PE cells were counted under the blue excitation. The difference between total counts and PE cell counts yielded the PC cell counts. At least 20 fields with the minimal of 200 cells per water sample were counted.

Oligonucleotide primers. When we started this project in 1998, there was only 1 complete rbcL gene sequence available for marine Synechococcus (WH7803) in the GenBank (Watson \& Tabita 1996). Although PCR primers became available to amplify a 480 to $483 \mathrm{bp}$ fragment of rbcL gene in 1997 (Pichard et al. 1997), the primers are degenerate and not specific for marine Synechococcus. A reverse degenerate PCR primer that is specific for Form IA Synechococcus has recently been published (Wawrik et al. 2003). Our goal was to design a set of non-degenerate primers specific for marine Synechococcus which can be extended for denaturing gradient gel electrophoresis (DGGE) or terminal restriction fragment length polymorphisms (T-RFLP) analysis of natural marine Synechococcus populations.

In this study, 2 primer sets were used to amplify the rbcL gene from various marine Synechococcus isolates and a third primer set was developed for environmental Synechococcus. The first primer set (WHF1 and WHR1) was used to amplify the rbcL gene from all the PE strains. This primer set was designed based on aligned nucleotide sequences of the rbcL genes of all the freshwater cyanobacteria and WH7803. The WHF1/WHR1 are non-degenerate primers and specific for WH7803 strain. The sequences of WHF1 and WHR1 are 5'-ATGAGCAAGAAGTACGA-3' (sequence position of $1-18$ as for WH7803) and 5'-GGTCTCCTGCTCGGACAG-3' (sequence position of $655-670$ as for WH7803), respectively. The rbcL gene from all the PE strains in Table 1 was amplified with WHF1/WHR1, and sequenced afterwards.

The second set of rbcL primers (CF1 and CR1) was designed based on the conserved regions on the rbcL sequences of 10 known PE strains and other cyanobacterial strains. This primer set was used to amplify the rbcL genes from PC strains that could not be amplified with WHF1/WHR1. The sequences for CF1 and CR1 are $5^{\prime}$-AC(TC)TACT(GA)GACTCC(TC)GAT TAC-3' (sequence position of 43-63 as for WH7803) and 5'-GAA(GA)GGCTG(GA)GAGTT(GA)ATGTT-3' (sequence position of 589-610 as for WH7803). The rbcL gene from all the PC strains was amplified using CF1/CR1.
The third primer set MSF1 and MSR1 was designed to specifically amplify the rbcL gene from the Marine Synechococcus Clade (in Form IA, see Fig. 4). The primer MSF1 contained oligonucleotide sequence 5'-GGTCCACTGTGTGGTCCGAGG-3' which corresponds to the sequence position of 88-105 (173-192) as for WH7803. The primer MSR1 has the nucleotide sequence 5'-GTTCTCGTCGTCCTTGGTGAAGTC-3', which corresponds to the sequence position of 568-591 as for WH7803. The non-degenerate MSF1/ MSR1 primers were tested against the natural bacterial communities in the Chesapeake Bay, with the goal to develop rapid fingerprinting techniques like DGGE for monitoring Synechococcus populations in the natural marine ecosystem.

Field sample collection. Water samples were collected from $2 \mathrm{~m}$ deep water of Chesapeake Bay and other estuarine stations (Fig. 1) using Niskin bottles on board the RV 'Cape Henlopen' on September 26-30, 2002. Water samples from the Roosevelt Inlet, Lewes, Delaware, were collected from surface water at the dock using a plastic bucket. For each station, $250 \mathrm{ml}$ water was filtered through $0.2 \mu \mathrm{m}$ pore-size polycarbonate filters (47 $\mathrm{mm}$ diameter, Millipore) and microbes retained on the filters were stored at $-20^{\circ} \mathrm{C}$ until DNA extraction.

Nucleic acid extraction. Total DNA was extracted according to a protocol developed by Schmidt et al. (1991) with minor modifications. Briefly, DNA from the bacterial community was extracted by treating with lysozyme and proteinase $\mathrm{K}$ concomitant with phenol extraction and isopropanol precipitation. The DNA was dissolved in $\mathrm{ddH}_{2} \mathrm{O}$ and stored at $-20^{\circ} \mathrm{C}$ for further analysis.

PCR amplification. For Synechococcus isolates, DNA released from boiled cultures was used as templates. For preparation of cell lysis, Synechococcus cultures were harvested by centrifugation at $10000 \mathrm{rpm}$ for $5 \mathrm{~min}$. Culture pellets were re-suspended in $50 \mu \mathrm{l}$ of lysis solution (0.1M Tris-HCl, $\mathrm{pH} 8.0,0.01 \% \mathrm{P}-40)$ and boiled for $5 \mathrm{~min}$. PCR was conducted in $0.2 \mathrm{ml}$ tubes with a final volume of $25 \mu \mathrm{l}$ reaction mixture, which contained 1 Unit of Taq DNA polymerase (Promega), $200 \mu \mathrm{M}$ of each dNTP, $1.5 \mathrm{mM}$ of $\mathrm{MgCl}_{2}, 1 \mu \mathrm{M}$ each of oligonucleotide primer and $1 \mu \mathrm{l}$ of cell lysates. For the primer set WHF1 and WHR1, the PCR amplification profile consisted of an initial denaturation at $94^{\circ} \mathrm{C}$ for 3 min, followed by 30 cycles of $94^{\circ} \mathrm{C}$ for $1 \mathrm{~min}, 50^{\circ} \mathrm{C}$ for 1 $\min$, and $72^{\circ} \mathrm{C}$ for $1 \mathrm{~min}$. The PCR condition for the primer sets CF1 and CR1 was similar to WHF1/WHR1, except that the annealing temperature for CF1/CR1 was increased to $55^{\circ} \mathrm{C}$.

The primer set MSF1/MSR1 was used to amplify the rbcL gene from the environmental DNAs. The PCR program for primers MSF1/MSR1 included an initial 


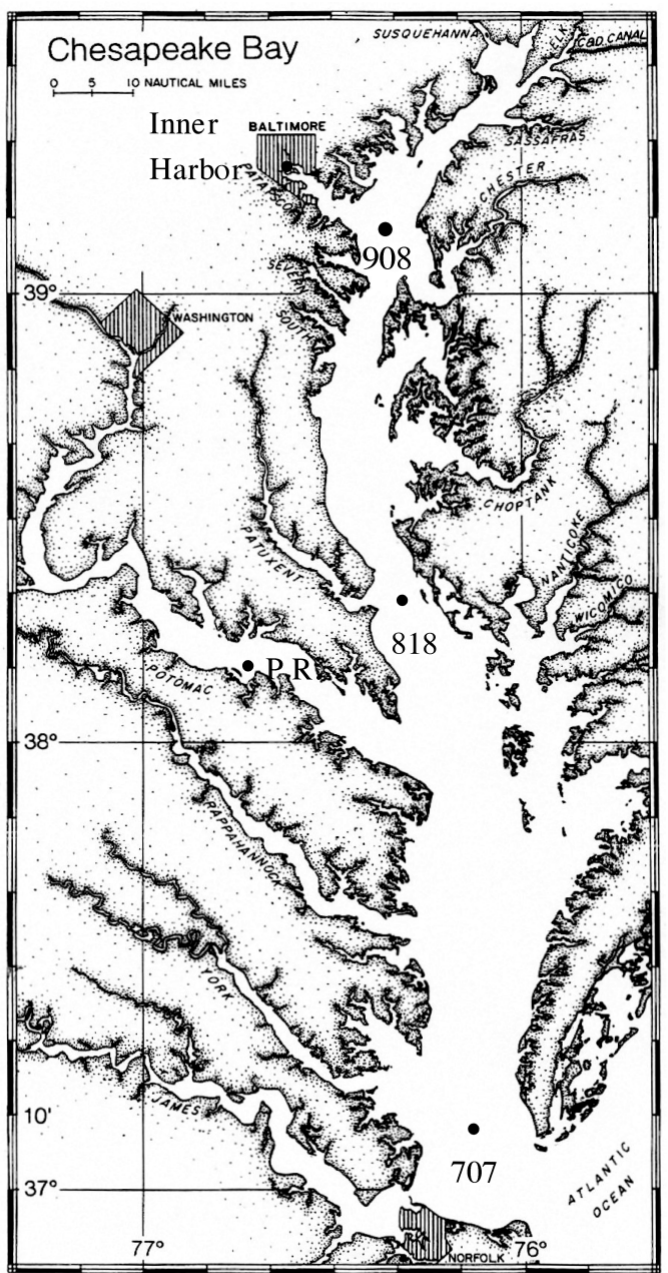

Fig. 1. Sampling locations in the Chesapeake Bay. Water samples were taken at $2 \mathrm{~m}$ depth. At the time of sampling, the salinity at Stns 908, 818, 707, and Potomac River (PR) was 15, 17,26 , and $0 \%$, respectively. The salinity of Lewes Dock $\left(38^{\circ} 46^{\prime} \mathrm{N}, 75^{\circ} 08^{\prime} \mathrm{W}\right.$ ) in the Delaware Bay (not shown on the map) is about $8 \%$

denaturation at $94^{\circ} \mathrm{C}$ for $5 \mathrm{~min}$ and 10 touchdown cycles of denaturation at $94^{\circ} \mathrm{C}$ for $1 \mathrm{~min}$, annealing at $65^{\circ} \mathrm{C}$ (with temperature decreasing $1^{\circ} \mathrm{C}$ per cycle) for $1 \mathrm{~min}$, and extension at $72^{\circ} \mathrm{C}$ for $1 \mathrm{~min}$, followed by 25 cycles of $94^{\circ} \mathrm{C}$ for $1 \mathrm{~min}, 55^{\circ} \mathrm{C}$ for $1 \mathrm{~min}$, and $72^{\circ} \mathrm{C}$ for $1 \mathrm{~min}$. The final extension of PCR amplification was at $72^{\circ} \mathrm{C}$ for $10 \mathrm{~min}$. PCR amplicons were examined by electrophoresis in $1 \%$ agarose gel stained with ethidium bromide in 0.5X TBE buffer. Gel images were captured and analyzed using Kodak EDAS 290 electrophoresis documentation and analysis system (Eastman Kodak).

Clone library construction. The 5 PCR products amplified from environmental samples were cloned. Each PCR product was purified by using Wizard PCR Prep DNA Purification System (Promega). The purified
DNA fragments were cloned into the pGEM-T Easy cloning vector (Promega) and then transformed into JM109 competent cells (Promega) according to the manufacturer's instructions. Positive clones (whitecolonies) were picked randomly and transferred onto a new agar plate for further use.

Restriction fragment length polymorphism (RFLP) analysis. To avoid redundant sequencing, the rbcL clones amplified from 5 estuarine microbial communities were pre-screened with RFLP. About 50 to 60 positive clones from each clone library were randomly picked and the plasmid inserts were PCR-amplified with vector-specific primers T7 (5'-TAATACGACTCACTATAGGGCGA-3') and SP6 (5'-ATTTAGGTGACACTATAG-3') along with Taq DNA polymerase (Promega). PCR amplification cycles involved a 3 min initial denaturation at $94^{\circ} \mathrm{C}$ and followed by 35 cycles of $94^{\circ} \mathrm{C}$ for $1 \mathrm{~min}, 56^{\circ} \mathrm{C}$ for $1 \mathrm{~min}, 72^{\circ} \mathrm{C}$ for $2 \mathrm{~min}$, and a 5 min final extension at $72^{\circ} \mathrm{C}$. Once a clone was confirmed to contain an insert of the appropriate size (ca. $510 \mathrm{bp}$ ), the insert was subjected to RFLP analysis. A subsample $(10 \mu \mathrm{l})$ from each PCR mixture was digested with $5 \mathrm{U}$ HaeIII in $1 \times$ Buffer $\mathrm{C}$ (Promega) at $37^{\circ} \mathrm{C}$ overnight in a final reaction volume of $25 \mu \mathrm{l}$. Digested DNA was separated by $2 \%$ agarose gel electrophoresis as described above. The resulting RFLP patterns were examined and compared by visual check. The distinguishable RFLP patterns were assigned as operational taxonomic units (OTUs).

Sequencing and phylogenetic analysis. Prior to sequencing, PCR products were purified using the DNA Purification System, Wizard DNA Clean-up (Promega) according to the manufacturer's protocol. Purified PCR products were then sequenced using an automated sequencer ABI310 (PE Applied Biosystems) in the Biological and Analytical Laboratory at the Center of Marine Biotechnology, University of Maryland Biotechnology Institute. Both strands of the DNA were sequenced if there were uncertain nucleotides in the first strand of DNA. Sequence alignment and phylogenetic reconstruction were conducted using Mac Vector 7.1 program (GCG). Jukes-Cantor distance matrix analysis was used to calculate the distances from the aligned DNA sequences, and the neighborjoining method was used to construct phylogenetic tree. To construct a phylogenetic tree based on the deduced amino acids, the pairwise similarity was calculated by using Blosum30 as matrix with open gap penalty of 10.0 and extend gap penalty of 0.1 . The phylogenetic tree was constructed by using the neighbor-joining method based on 166 amino acid residues. Bootstrap values for both trees were obtained from analysis of 1000 re-samplings of the data set.

Nucleotide sequence accession numbers. The nucleotide sequences determined in this study have been 
deposited in GenBank. The assigned accession numbers for the Synechococcus strains used in this study are shown in Table 1. The assigned accession numbers for OTUs are as follows: OTU1 (AY453140), OTU2 (AY453144), OTU3 (AY453145), OTU4 (AY453148), OTU5 (AY453149), OTU6 (AY453150), OTU7 (AY453152). The reference strains retrieved from GenBank included Anabaena sp. PCC7120 (P00879), Chromatium vinosum (M26396), Cylindrotheca sp. (P24673), Heterosigma akashiwo (M24288), Nitrobacter winogradskyi (AF109915), Prochlorococcus marinus CCMP1378 (ZP_00104542), P. marinus MIT9313 (ZP_00113526), Prochlorothrix hollandica (P27568), Rhodobacter capsulatus (L82000), Synechococcus PCC6301 (J01536), Synechococcus PCC7002 (Q44176), Synechocystis PCC6803 (D64000), Thiobacillus denitrificans (L42940), T. ferrooxidans A (Q07087), T. ferrooxidans B (P28895), and Trichodesmium erythraeum IMS101 (ZP_00072133).

\section{RESULTS AND DISCUSSION}

\section{Characterization of Chesapeake Bay Synechococcus isolates}

Among 13 CB strains, 7 strains are the PC type (or non-PE type) and 6 strains are the PE type (Table 1). The absorption spectra of Chesapeake Bay PC strains were similar to that of Synechococcus WH8101 in MC-B, while the PE strains isolated from the bay have an absorption spectrum similar to WH7805 (data not shown). Microscopic examination suggested that the vast majority of colonies consist of small unicellular cyanobacteria ranging in size from 1 to $3 \mu \mathrm{m}$. Through the course of isolation of Synechococcus from the Chesapeake Bay, we found that most of colonies (80 to $95 \%$ of all colonies) recovered from the Baltimore Inner Harbor and upper Chesapeake Bay (with salinity $<15 \%$ ) were green strains. The percentage of the green colonies grown on the plate decreased to 56 to $65 \%$ at the mouth of the bay (Stn 707) where salinity is typically in the range of 20 to $30 \%$. The percentage of pigment types estimated based on the colonies recovered from the pre-incubated samples may not reflect the actual distribution of PC and PE Synechococcus in the bay. Further examination of original water samples using epifluorescence microscopy showed that PC type Synechococcus were predominant (ca. $87 \%$ ) in the upper bay and Baltimore Inner Harbor, while PE type Synechococcus could account for approximately $82 \%$ of total Synechococcus populations in the lower bay (Stn 707) (Fig. 2). The ratio of PC versus PE type appeared to decrease from the upper to the lower bay (Fig. 2).
Six CB strains (CB0101, CB0104, CB0201, CB0205, CB0208, CB0210) were able to grow in the SN medium with wide range of salinity $(0,15$, and $30 \%$, respectively), although their growth rate varied slightly with the amount of salt amended. In contrast, WH7803 and WH7805 could not survive in the SN medium with $0 \%$ salinity. These data suggest that the Chesapeake Bay Synechococcus have been adapted to the estuarine ecosystem.

Interestingly, several motile strains were found in the lower bay where PE strains were relatively more abundant compared to the upper bay. Five CB strains (CB0101, CB0205, CB0206, CB0207, and CB0208) were motile, and 4 of them were PE type (Table 1). The motile Synechococcus strains were thought to be more common in the oligotrophic waters, and they are not usually found in nutrient-rich coastal regions (Olson et al. 1990, Palenik 1994, Toledo et al. 1999).

\section{Most of Chesapeake Bay Synechococcus isolates belong to the MC-B cluster}

The phylogenetic tree based on the rbcL DNA sequences of $\mathrm{CB}$ strains and the bay samples revealed that Synechococcus living in the Chesapeake Bay are very diverse (Fig. 3). The CB strains alone exhibited the genetic diversity equivalent to the Woods Hole PC strains WH5701, WH8007 and WH8101 which were isolated from Long Island Sound, the Pier Harbor of Woods Hole Oceanography Institute, and the Gulf of Mexico, respectively. All the PE strains (Woods Hole collection) isolated from the Sargasso Sea and the Gulf of Mexico by Waterbury and Brand (see Table 1) were clustered within the MC-A group. Surprisingly, all the Chesapeake Bay PE strains (except for CB0205) were not clustered with the Woods Hole PE isolates in the MC-A group (Fig. 3). Instead, the 5 PE strains (CB0206,

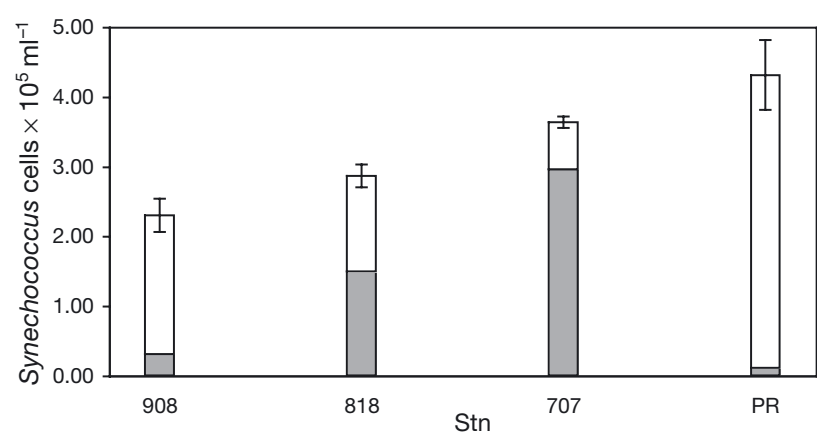

Fig. 2. Concentration of PC and PE type Synechococcus at Stns 908, 818 and 707, and in the Potomac River. Error bars represent SD of total cell counts. Closed bar: PE type; open bar: PC type 


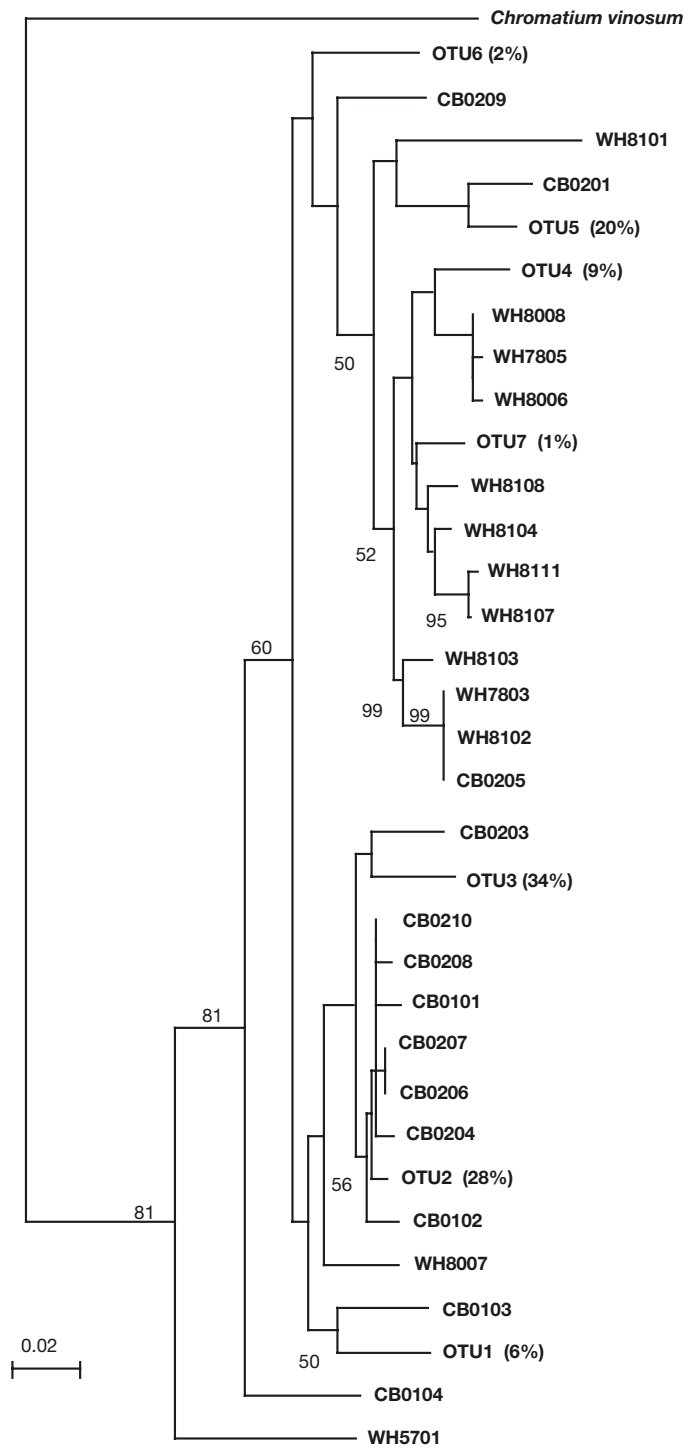

Fig. 3. Neighbor-joining tree of marine Synechococcus strains constructed using the partial rbcL nucleotide sequences (414 bases). OTUs included in this tree represent the 7 distinct environmental rbcL genotypes (shown in Fig. 6). Percentages in the parenthesis are the relative distribution frequency of each OTU among 233 rbcL clones analyzed. Numbers at tree branches indicate bootstrap values with 1000 replicates. Bootstrap values less than 50 are not shown. Scale bar indicates 0.02 substitution per site

CB0207, CB0208, CB0209 and CB0210) from the bay were closely related to WH8007, a member of MC-B (Fig. 3). Our data here suggested that the MC-B cluster not only contains the PC type Synechococcus, but also the PE type Synechococcus. Out of 13 CB isolates, 9 were grouped with $\mathrm{WH} 8007$, but none of them were closely related to WH5701. CB0104 appeared to be in between WH5701 and WH8007. We believe that at least $10 \mathrm{CB}$ strains can be considered as belonging to
MC-B (or Subcluster 5.2) which currently only contains WH8007 and WH5701.

According to the rbcL phylogeny, WH8101 could be clustered within the MC-A group, but with a relatively deep and independent branch. Recently, WH8101 has been re-classified into the MC-A or subcluster 5.1 (Herdman et al. 2001), and the close relationship between WH8101 and the MC-A group were also supported by the 16S-23S ribosomal DNA internal transcribed sequences (Rocap et al. 2002) and 16S rDNA gene sequences (Fuller et al. 2003), respectively. With $\mathrm{PE}$ strains found in the MC-B cluster and PC strains in the MC-A cluster, it is believed that pigment types ( $\mathrm{PE}$ or $\mathrm{PC}$ ) are no longer a critical feature for separating MC-A and MC-B Synechococcus. Moreover, the designation of $\mathrm{MC}-\mathrm{B}$ should be redefined when more data are available.

The rbcL gene phylogeny also demonstrated that motile strains are closely related, but not necessary monophyletic. For example, 4 motile CB strains (CB0101, CB0206, CB0207 and CB0208) were closely related in MC-B, while 1 motile CB strain (CB0205) was tightly associated with WH8102 and WH8103 in MC-A (Fig. 3). A previous study focused on the MC-A strains showed that motile strains of Synechococcus form a monophyletic group (Toledo et al. 1999). Our result and a recent study based on 16S rDNA gene sequences (Fuller et al. 2003) both indicated that motile strains could also be found in MC-B representing a second group of motile Synechococcus. These findings suggested that classification or clustering of Synechococcus should not be simply concluded based on certain phenotypic features like motility. Our effort for isolating bacterial strains from natural environments is limited. In reality, we may not be able to find a clear boundary among Synechococcus based on phenotypic characteristics when more and more 'inbetween' strains are discovered. It seems very likely that the genus Synechococcus (Cyanobacteria) is polyphyletic and its classification needs to be re-evaluated (Honda et al. 1999, Robertson et al. 2001).

\section{Synechococcus strains from estuarine, coastal and oceanic waters form a monophyletic group}

The phylogenetic affiliation at the amino acid sequence level showed that all the estuarine, coastal and oceanic Synechococcus used in this study, together with marine Prochlorococcus marinus, share a common ancestry and belong to the Form IA RuBisCO (Fig. 4). Prochlorococcus marinus MIT9313 and CCMP1378 were closely related to each other, and also formed a close relationship with the marine Synechococcus cluster. The chemoautotrophic bacteria (e.g. 


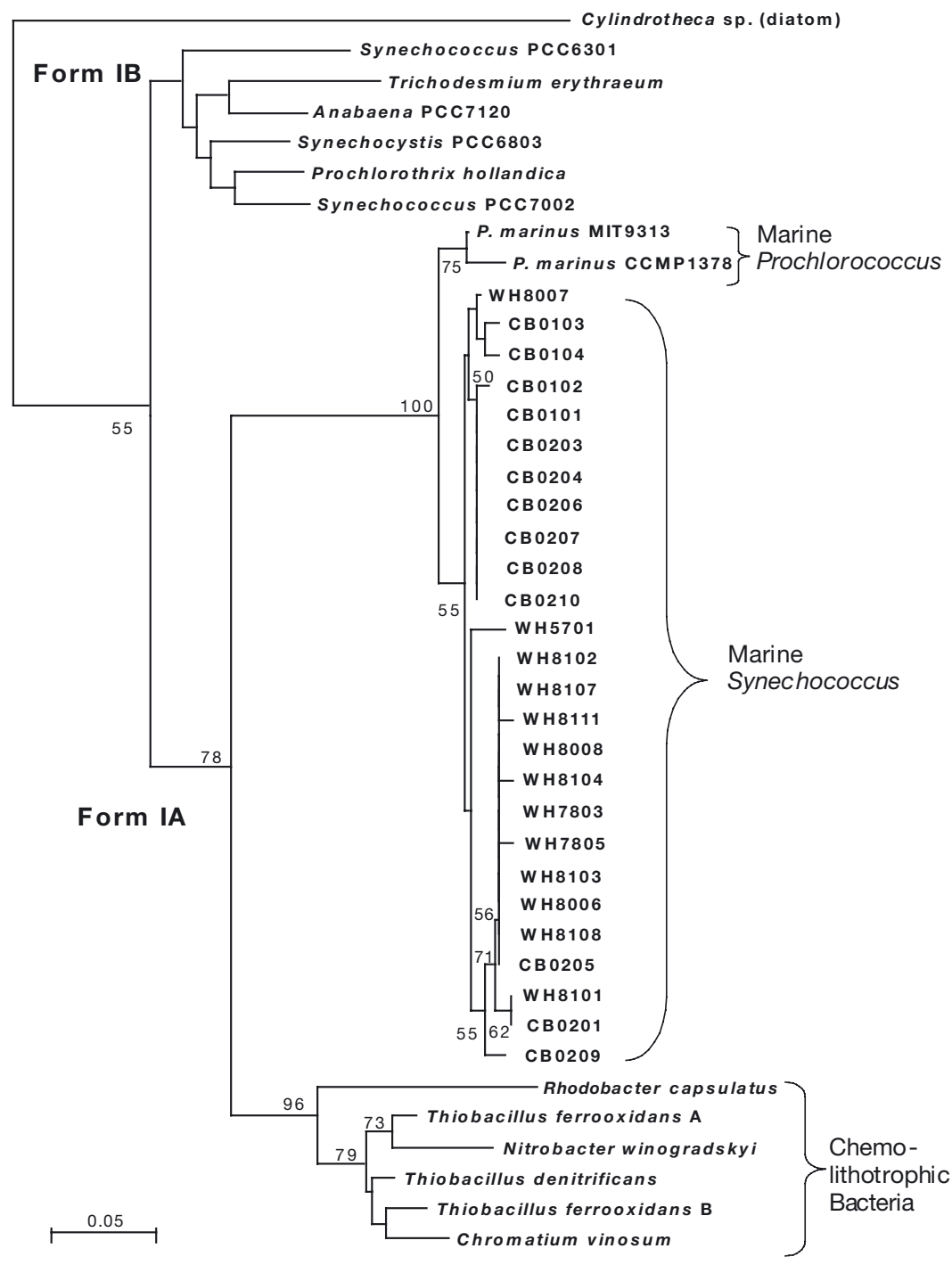

Fig. 4. Phylogenetic tree constructed using the neighbor-joining method based on the aligned rbcL amino acid sequences (138 residues). Forms IA and IB are the 2 major groups of RuBisCO. Numbers at tree branches indicate bootstrap values with 1000 replicates. Bootstrap values less than 50 are not shown. Scale bar indicates 0.05 substitution per site

Synechococcus strains formed a monophyletic group (termed marine Synechococcus Clade) that is closely related to marine Prochlorococcus. The close relationship between marine Synechococcus and marine Prochlorococcus revealed by the rbcL gene phylogeny is consistent with the previous studies based on the 16S rDNA sequences (Palenik \& Haselkorn 1992, Urbach et al. 1992). The rbcL phylogeny also showed a close relationship between marine unicellular cyanobacteria and chemolithotrophic bacteria (Fig. 4). Our results further support previous studies in which the Prochlorococcus marinus and Synechococcus strain WH7803 rbcL sequences are found most closely related to the gamma-purple bacterial sequences (Watson \& Tabita 1996, 1997). It is very likely that marine Synechococcus and Prochlorococcus acquired the rbcL gene from a chemolithotroph through lateral gene transfer (Watson \& Tabita 1997).

Our result does not support a previous study in which marine Synechococcus WH8007 was clustered into the Form IB group based on the rbcL gene phylogeny (Pichard et al. 1997). In our study, the rbcL gene sequence of WH8007, together with other marine Synechococcus were all clustered into the Form IA group. Pichard et al. (1997) also indicated that the 2 Prochlorococcus strains were clustered together with freshwater Synechococcus in the Form IB group. However, the phylogenetic analysis based on the various molecular markers (e.g. 16S rDNA, 16S-23S ITS, rpoC1 and rbcL) did not support such a close relationship between Prochlorococcus and freshwater Synechococcus (Palenik \&

Chromatium vinosum, Nitrobacter winogradskyi, Rhodobacter capsulatus, Thiobacillus denitrificans, T. ferrooxidans) were in another branch of the Form IA RuBisCO. All the freshwater cyanobacteria (e.g. Anabaena PCC7120, Synechococcus PCC6301 and PCC7002 and Synechocystis PCC6803) and marine filamentous cyanobacteria Trichodesmium erythraeum were within the Form IB RuBisCO.

Despite the wide range of salinity distribution in the Chesapeake Bay, all the CB strains (13 isolates) are still more closely related to the WH strains than to the freshwater Synechococcus, which were grouped within the Form IB RuBisCO (Fig. 4). The CB and WH
Haselkorn 1992, Urbach et al. 1992, Shimada et al. 1995, Watson \& Tabita 1997, Badger et al. 2002, Rocap et al. 2002).

\section{Development of marine Synechococcus-specific primers based on the rbcL gene}

Because all marine Synechococcus form a unique cluster, a set of non-degenerate PCR primers that are specific to this group of unicellular cyanobacteria was developed. The upstream primer MSF1 is specific for marine Synechococcus strains while the downstream primer 
MSR1 is specific for marine Synechococcus, marine Prochlorococcus, some chemoautotrophic bacteria and freshwater Synechococcus. The primer set (MSF1/ MSR1) was tested against the bacterial DNA recovered from several estuarine samples where the salinity ranged from 0 to $30 \%$. In all cases, specific PCR amplification was achieved (Fig. 5), suggesting that this primer set is suitable to amplify the rbcL gene from Synechococcus populations in various marine environments.

There are several reasons for developing nondegenerate rbcL primers that are specific for marine Synechococcus. First, this primer set will allow us to explore the genetic diversity of Synechococcus in the natural marine environment. Non-degenerate primers can also be coupled with rapid fingerprinting techniques such as DGGE or T-RFLP to monitor the Synechococcus populations over temporal and spatial scales. Second, non-specific PCR amplification is greatly minimized using the rbcL primers because the rbcL gene mainly exists in phototrophs and some chemolithotrophs. PCR amplification with the rbcL

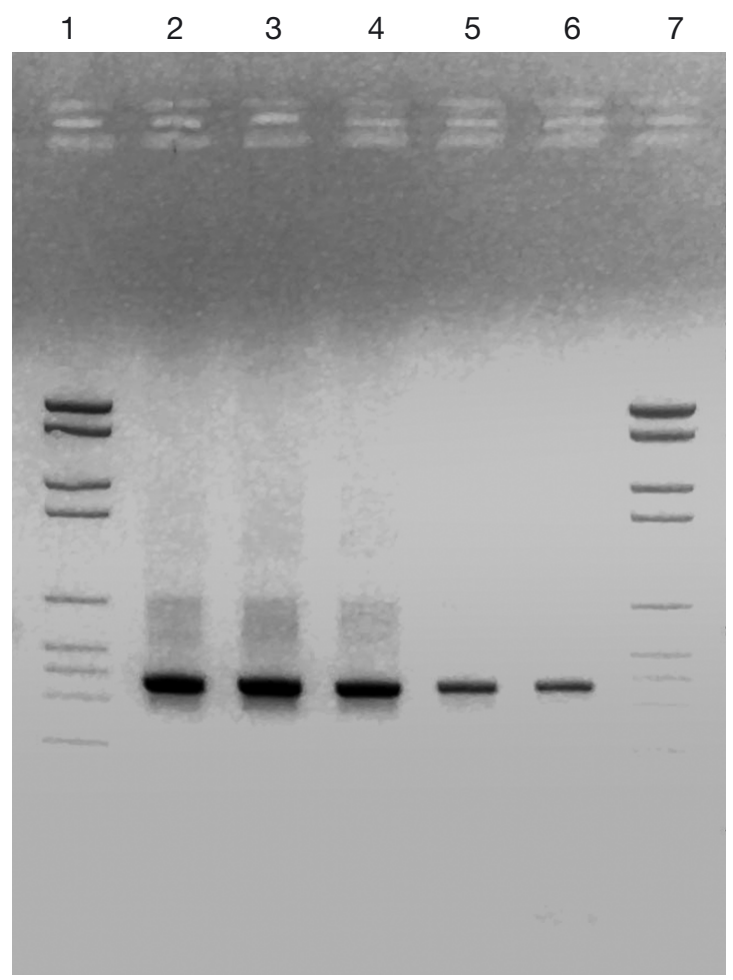

Fig. 5. PCR amplification of the rbcL gene from natural marine bacterial communities using the primer set MSF1/MSR1, which is specific for marine Synechococcus. Lanes 1 and 7 correspond to Molecular Weight Marker VI (Roche) (from top to bottom: 2176, 1766, 1230, 1033, 653, 517, 453, 394, 298, 234/220, $154 \mathrm{bp}$, respectively). Lanes 2 to 6 correspond to bacterial communities from Stns 908 (Upper Bay), 818 (Mid Bay) and 707 (Lower Bay) of Chesapeake Bay, Potomac River, and Lewes Dock (Roosevelt Inlet, Delaware)

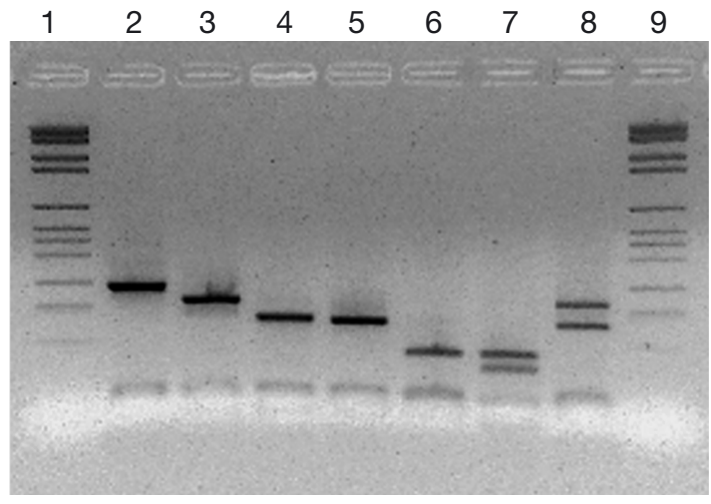

Fig. 6. Seven different rbcL genotypes or OTUs revealed by RFLP analysis (Lanes 2 to 8) of rbcL clone libraries (a total of 232 clones). Lanes 1 and 9 are Molecular Marker VI. The reversed image is shown

primers can improve the specificity and avoid the contamination problem associated with 16S rDNA primers. Third, the rbcL gene sequences (also rpoC1 and ITS sequences) provide greater level of genetic resolution relative to the $16 \mathrm{~S}$ rDNA gene sequences, and are particularly suitable for studying the phylogenetic relationship of closely related strains like Synechococcus. Finally, this primer set will allow us to study the ecological interaction between Synechococcus and cyanophage in the natural marine environment. Viruses that infect marine Synechococcus (synechophage) are ubiquitous and abundant in various marine environments (Suttle \& Chan 1993, 1994, Waterbury \& Valois 1993, Wilson et al. 1993, Lu et al. 2001). The group-specific PCR primers have been applied to investigate the genetic diversity of synechophage in the Chesapeake Bay and other marine environments (Fuller et al. 1998, Zhong et al. 2002, Marston \& Sallee 2003, Wang \& Chen 2004), so it would be ideal to have a specific primer set for their corresponding hosts. In order to understand the complex interaction between marine viruses and their microbial hosts, it is necessary to look at the genetic diversity of both viral and host communities (Fuhrman 1999).

\section{Highly diverse Synechococcus in the Chesapeake Bay}

At least 7 genotypes (or OTUs) of Synechococcus were found in the Chesapeake Bay based on the RFLP analysis of environmental rbcL clones (Fig. 6). All the estuarine stations except for Stn 707 contained at least 6 different OTUs (Fig. 7). The 7 OTUs recovered from the 4 stations in the Chesapeake Bay and Lewes Dock in the Delaware Bay were clustered within the marine Synechococcus clade (Fig. 3). Among 232 clones tested, $10 \%$ (OTUs 4 and 7) were clustered with PE 


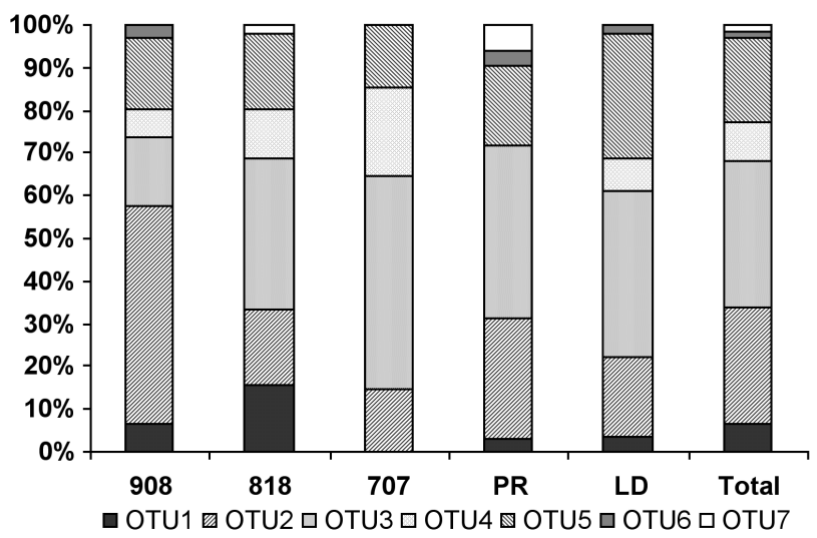

Fig. 7. Relative percentages of each OTU presented in each sampling location: Chesapeake Bay Stns 908, 818 and 707, Potomac River (PR) and Lewes Dock (LD). The relative distribution of each OTU among the total 232 clones is shown as 'Total'

strains in MC-A, $22 \%$ (OTUs 5 and 6) were related to WH8101 (PC strain in MC-A), and 68\% (OTUs 1, 2 and 3) were affiliated with the MC-B group (Fig. 7). The composition of environmental rbcL sequences suggests that Chesapeake Bay is dominated by the MC-B type Synechococcus.

In the Chesapeake Bay, the distribution of these Synechococcus genotypes changed from the upper to lower bay (Fig. 7). For example, from the upper bay (Stn 908) to lower bay (Stn 707), OTU2 gradually decreased from 51 to $15 \%$, while OTU3 steadily increased from 16 to $49 \%$, respectively. The dramatic change of Synechococcus populations in the Chesapeake Bay is reflected by the complicated ecological habitats in the bay. The Chesapeake Bay is an incredibly complex ecosystem in which salinity, temperature and nutrients are very dynamic both temporally and spatially. High salinity seawater from the Atlantic Ocean enters the mouth of the bay, and gradually decreases towards north. Salinity levels in the bay could range from near 0 to $30 \%$ across the north-south transaction. In our study, the OTUs were selected based on the RFLP digestion patterns of one restriction enzyme, and actual genetic diversity of Synechococcus in the bay could be underestimated using this method. In the California Current, 7 genetically distinct groups of Synechococcus have been identified based on the rpoC1 sequence data (Toledo \& Palenik 1997, Toledo et al. 1999, Ferris \& Palenik 1998, Palenik 2001).

\section{CONCLUSION}

Despite the great genetic diversity revealed by the rbcL gene sequences of Synechococcus isolates and environmental clones, Synechococcus populations in the Chesapeake Bay appear to be dominated by the MC-B (or Subcluster 5.2) type Synechococcus. Several novel PE strains within the MC-B cluster were found in the lower bay. All the CB strains are halotolerant, suggesting they have been adapted to the Chesapeake estuary where salinity could change from almost 0 to $30 \%$. Synechococcus in estuarine, coastal and oceanic waters (at least for MC-A and MC-B) are monophyletic rather than widely dispersed across the rbcL phylogenetic tree. With the marine Synechococcus-specific primers available, it is now possible to explore the genetic diversity of marine Synechococcus populations. At least 7 different genotypes of Synechococcus from the bay have been identified, and in most cases 6 distinct genotypes could be found in one sample. Our long-term goal is to explore the co-variation of both Synechococcus and their phage simultaneously in the natural aquatic environments. The spatial and temporal variations of Synechococcus populations, together with synechophage populations in the Chesapeake Bay are currently under investigation.

Acknowledgements. We thank the crew of the RV 'Cape Henlopen'. We thank all the scientists who participated in the MOVE (Microbial Observatories of Virioplankton Ecology) led by E. Wommack, F. Chen and W. Coats. We also thank B. Binder for providing several WH Synechococcus strains. This work was supported by grants from the National Science Foundation (OCE-0049098, MCB-0132070 and MCB-0238515).

\section{LITERATURE CITED}

Alfreider A, Vogt C, Hoffmann D, Babel W (2003) Diversity of ribulose-1,5-bisphosphate carboxylase/oxygenase large subunit genes from groundwater and aquifer microorganisms. Microb Ecol 45:317-328

Badger MR, Hanson D, Price GD (2002) Evolution and diversity of $\mathrm{CO}_{2}$ concentrating mechanisms in cyanobacteria. Funct Plant Biol 29:161-173

Brahamsha B (1996) A genetic manipulation system for oceanic cyanobacteria of the genus Synechococcus. Appl Environ Microbiol 62:1747-1751

Campbell L, Carpenter EJ, Iacono FJ (1983) Identification and enumeration of marine chroococcoid cyanobacteria by immunofluorescence. Appl Environ Microbiol 46:553-559

Campbell L, Iturriaga R (1988) Identification of Synechococcus spp. in the Sargasso Sea by immunofluorescence and fluorescence excitation spectroscopy performed on individual cell. Limnol Oceanogr 33:1196-1201

Clegg MT (1993) Chloroplast gene sequences and the study of plant evolution. Proc Natl Acad Sci USA 90:363-367

Douglas SE, Carr N (1988) Examination of genetic relatedness of marine Synechococcus spp. by using restriction fragment length polymorphisms. Appl Environ Microbiol 54: 3071-3078

Elsaied H, Naganuma T (2001) Phylogenetic diversity of ribulose-1,5-bisphosphatecarboxylase/oxygenase large-subunit genes from deep-sea microorganisms. Appl Environ Microbiol 67:1751-1765

Ferris MJ, Palenik B (1998) Niche adaptation in ocean cyanobacteria. Nature 396:226-228 
Ferris MJ, Kuhl M, Wieland A, Ward DM (2003) Cyanobacterial ecotypes in different optical microenvironments of a $68^{\circ} \mathrm{C}$ hot spring mat community revealed by $16-23 \mathrm{~S}$ rRNA internal transcribed spacer region variation. Appl Environ Microbiol 69:2893-2898

Fuhrman JA (1999) Marine viruses and their biogeochemical and ecological effects. Nature 399:541-547

Fuhrman JA, Campbell L (1998) Microbial microdiversity. Nature 393:410-411

Fuller NJ, Wilson WH, Joint IR, Mann NH (1998) Occurrence of a sequence in marine cyanophages similar to that of $\mathrm{T} 4$ gp20 and its application to PCR-based detection and quantification techniques. Appl Environ Microbiol 64: 2051-2060

Fuller NJ, Marie MD, Partensky F, Vaulot D, Pos F, Scanlan DJ (2003) Clade-specific 16S ribosomal DNA oligonucleotides reveal the predominance of a single marine Synechococcus clade throughout a stratified water column in the Red Sea. Appl Environ Microbiol 69:2430-2443

Gregory MF, Watson F, Tabita R (1997) Microbial ribulose 1,5-bisphosphate carboxylase: a molecule for phylogenetic and enzymeological investigation. FEMS Microbiol Lett 146:13-22

Herdman M, Castenholz RE, Iteman I, Waterbury JR, Rippka R (2001) Subsection I (Formerly Chroococcales Wettstein 1924, emend. Rippka, Deruelles, Waterbury, Herdman and Stanier (1979). In: Boone DR, Castenholz RW, Garrity GM (eds) Bergey's manual of systematic bacteriology, 2nd edn, Vol 1. The archaea and the deeply branching and phototrophic bacteria. Springer, New York p 493-514

Honda D, Yokota A, Sugiyama J (1999) Detection of seven major evolutionary lineages in cyanobacteria based on the 16S rRNA gene sequence analysis with new sequencers of five marine Synechococcus strains. J Mol Evol 48:723-739

Johnson P, Sieburth J (1979) Chroococcoid cyanobacteria in the sea: a ubiquitous and diverse phototrophic biomass. Limnol Oceanogr 24:928-35

Li WKW (1998) Annual average abundance of heterotrophic bacteria and Synechococcus in surface ocean waters. Limnol Oceanogr 43:1745-1753

Lu JR, Chen F, Hodson RE (2001) Distribution, isolation, host specificity and diversity of marine cyanophages infecting Synechococcus spp. in coastal estuary. Appl Environ Microbiol 67:3285-3290

Marston MF, Sallee JL (2003) Genetic diversity and temporal variation in the cyanophage community infecting marine Synechococcus species in Rhode Island's coastal waters. Appl Environ Microbiol 69:4639-4647

McFadden BA, Tabita FR (1974) D-ribulose 1,5-bisphosphate carboxylase and the evolution of autotrophy. BioSystems 6:93-112

Miziorko HM, Lorimer GH (1983) Ribulose 1,5-bisphosphate carboxylase-oxygenase. Annu Rev Biochem 52:507-535

Moore LR, Rocap G, Chisholm SW (1998) Physiology and molecular phylogeny of coexisting Prochlorococcus ecotypes. Nature 393:464-467

Olson RJ, Chisholm SW, Zettler ER, Altabet MA, Dusenberry JA (1990) Spatial and temporal distributions of prochlorophyte picoplankton in the North Atlantic Ocean. DeepSea Res 37:1033-1051

Palenik B (1994) Cyanobacterial community structure as seen from RNA polymerase gene sequence analysis. Appl Environ Microbiol 60:3212-3219

Palenik B (2001) Chromatic adaptation in marine Synechococcus strains. Appl Environ Microbiol 67:991-994

Palenik B, Haselkorn R (1992) Multiple evolutionary origins of prochlorophytes, the chlorophyll b-containing prokary- otes. Nature 355:265-267

Partensky F, Blanchot J, Vaulot D (1999) Different distribution and ecology of Prochlorococcus and Synechococcus in oceanic waters: a review. Bull Inst Oceanogr Fish 19: $457-475$

Pichard SL, Campbell L, Paul JH (1997) Diversity of the ribulose bisphosphate carboxylase/oxygenase form I gene (rbcL) in natural phytoplankton communities. Appl Environ Microbiol 63:3600-3606

Robertson BR, Tezuka N, Watanabe MM (2001) Phylogenetic analyses of Synechococcus strains (cyanobacteria) using sequences of $16 \mathrm{~S}$ rDNA and part of the phycocyanin operon reveal multiple evolutionary lines and reflect phycobilin content. Int J Syst Evol Microbiol 51:861-871

Rocap G, Distel DL, Waterbury JB, Chisholm SW (2002) Resolution of Prochlorococcus and Synechococcus ecotypes by using 16S-23S ribosomal DNA internal transcribed spacer sequences. Appl Environ Microbiol 68:1180-1191

Scanlan DJ, West NJ (2002) Molecular ecology of the marine cyanobacterial genera Prochlorococcus and Synechococcus. FEMS Microbiol Rev 40:1-12

Schmidt TM, Delong EF, Pace NR (1991) Analysis of a marine picoplankton community by $16 \mathrm{~S}$ rRNA gene cloning and sequencing. J Bacteriol 173:4371-4378

Shimada AS, Kanai T, Maruyama T (1995) Partial sequence of ribulose-1,5-bisphosphate carboxylase/oxygenase and the physiology of Prochloron and Prochlorococcus (Prochlorales). J Mol Evol 40:671-677

Suttle CA, Chan AM (1993) Marine cyanophages infecting oceanic and coastal strains of Synechococcus: abundance, morphology, cross-infectivity and growth characteristics. Mar Ecol Prog Ser 92:99-109

Suttle CA, Chan AM (1994) Dynamics and distribution of cyanophages and their effect on marine Synechococcus spp. Appl Environ Microbiol 60:3167-3174

Toledo G, Palenik B (1997) Synechococcus diversity in the California current as seen by RNA polymerase (rpoC1) gene sequences of isolated strains. Appl Environ Microbiol 63:4298-4303

Toledo G, Palenik B, Brahamsha B (1999) Swimming marine Synechococcus strains with widely different photosynthetic pigment ratios form a monophyletic group. Appl Environ Microbiol 65:5247-5251

Tolker-Nielson T, Holmstrøm K, Molin S (1997) Visualization of specific gene expression in individual Salmonella typhimurium cells by in situ PCR. Appl Environ Microbiol 63:4196-4203

Urbach E, Robertson DL, Chisholm SW (1992) Multiple evolutionary origins of prochlorophytes within the cyanobacterial radiation. Nature 355:267-270

Urbach ED, Scanlan DJ, Distel DL, Waterbury JD, Chisholm SW (1998) Rapid diversification of marine picophytoplankton with dissimilar light-harvesting structures inferred from sequences of Prochlorococcus and Synechococcus (Cyanobacteria). J Mol Evol 46:188-201

Wang K, Chen F (2004) Spatial and temporal variation of cyanophage communities in the Chesapeake Bay revealed by T-RFLP. Aquat Microb Ecol 34:105-116

Waterbury JB, Rippka R (1989) Order Chroococcales (Wettstein 1924, emend. Rippka et al. 1979). In: Staley JT, Bryant MP, Pfennig N, Holt JG (eds) Bergey's manual of systematic bacteriology, Vol 3. Williams Wilkins, Baltimore, MD, p 1728-1739

Waterbury JB, Valois FW (1993) Resistance to co-occurring phages enables marine Synechococcus communities to coexist with cyanophages abundant in seawater. Appl Environ Microbiol 59:3393-3399 
Waterbury JB, Willey JM (1988) Isolation and growth of marine planktonic cyanobacteria. Methods Enzymol 167: 100-105

Waterbury JB, Watson SW, Guillard RRL, Brand LE (1979) Widespread occurrence of a unicellular, marine, planktonic cyanobacterium. Nature 277:293-294

Waterbury JB, Watson SW, Valois FW, Franks DG (1986) Biological and ecological characterization of the marine unicellular cyanobacterium Synechococcus. Can Bull Fish Aquat Sci 214:159-204

Watson GMF, Tabita FR (1996) Regulation, unique gene organization, and unusual primary structure of carbon fixation genes from a marine phycoerythrin-containing cyanobacterium. Plant Mol Biol 32:1103-1115

Watson GMF, Tabita FR (1997) Microbial ribulose 1,5-bisphosphate carboxylase/oxygenase: a molecule for phylogenetic and enzymological investigation. FEMS Microbiol

Editorial responsibility: Jed Fuhrman,

Los Angeles, USA
Lett 146:13-22

Wawrik B, Paul JH, Campbell L, Griffin D, Houchin L, FuentesOrtega A, Muller-Karger F (2003) Vertical structure of the phytoplankton community associated with a coastal plume in the Gulf of Mexico. Mar Ecol Prog Ser 251:87-101

Wilson WH, Joint IR, Carr NG, Mann NH (1993) Isolation and molecular characterization of five marine cyanophages propagated on Synechococcus sp. strain WH7803. Appl Environ Microbiol 59:3736-3743

Wood AM, Townsend D (1990) DNA polymorphism within the WH7803 serogroup of marine Synechococcus spp. (Cyanobacteria). J Phycol 26:576-585

Zhong Y, Chen F, Lu JR, Poorvin L, Wilhelm S, Hodson R (2002) Phylogenetic diversity of marine cyanophage isolates and natural virus communities as revealed by sequences of viral capsid assembly protein gene g20. Appl Environ Microbiol 68:1576-1584

Submitted: July 24, 2003; Accepted: April 15, 2004

Proofs received from author(s): July 19, 2004 